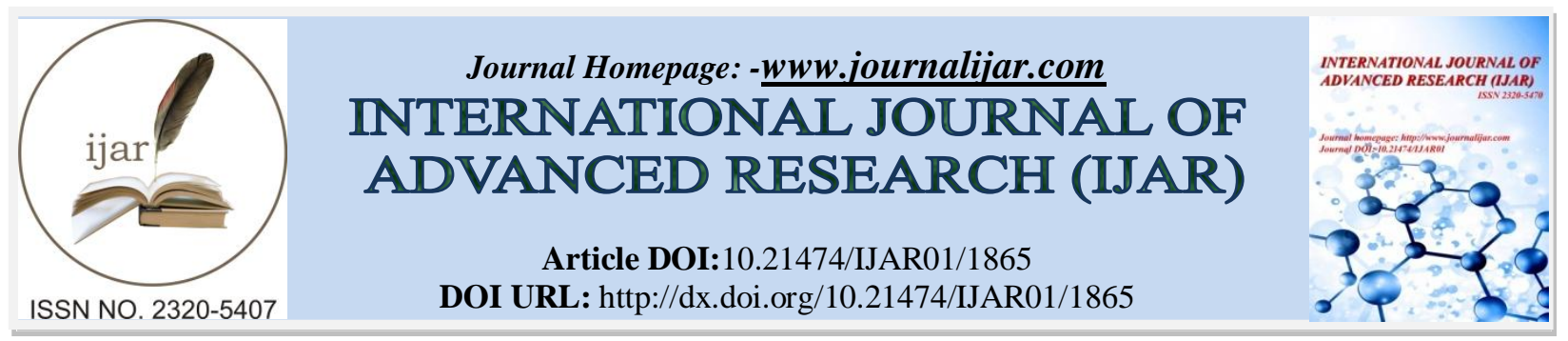

RESEARCH ARTICLE

\title{
DEVELOPMENT OF COMPOSITION OF COMPLEX ACTION TO DEAL WITH COMPLICATIONS AT OIL PRODUCTION.
}

\author{
Saltanat Elikbayevna Baibotayeva ${ }^{1}$, Gulnaz Zhaksylykovna Moldabayeva ${ }^{1}$, Kazim Sadykovich Nadirov ${ }^{2}$, \\ Sadyrbayeva Ainur Slambekovna ${ }^{2}$ and Kutzhanova Ashan Nurtayevna ${ }^{2}$. \\ 1. Kazakh National Research Technical University named after K.I. SatpayevKazakhstan, 050013,Almaty, \\ Satpayev Street, 22. \\ 2. South-Kazakhstan state University. M. Auezov, Kazakhstan, 160012, Shymkent, Tauke-Khan Avenue5
}

\section{Manuscript Info}

Manuscript History

Received: 12 August 2016

Final Accepted: 23 September 2016

Published: October 2016

Key words:-

Composition of complex action, a demulsifier, oxyethylated fatty acids, trietanolamine,demulsifying action, asfaltene deposits, corrosion, inhibitors of paraffin formation.

\section{Abstract}

The aim of the research was to investigate the complex action of the new composition received with using the wastage of the fat and oil industry as demulsifiers and corrosion inhibitors and paraffin wax formation. Today serious problems which exist in oil-extracting branch are corrosion of the oil-field equipment, formation of resistant water oil emulsions and education of theasphalt paraffin depositions. These phenomena considerably complicate the extraction of oil from wells, negatively influence on work of the oil-extracting equipment, pipeline communications. One of the effective directions in creation of new reagents for fight against complications in case of oil production is the compounding of surface-active substances of various structure allowing, in the presence of a certain set of initial components, to receive structures with various properties. In consist of such compositions includes several individual compounds in the mixture exhibiting a synergistic effect; in consist of compositions can be included surfactant species with properties of wetting agent, dispersant, coagulator and etc. Such compositions usually along with properties inherent in individual components included in their composition, have a set of properties resulting from their joint action. This way allows to strengthen the most important characteristics of reagents and to expand their functional action. The semi-industrial testing of new composition executed on oils of the field Kumkol and model emulsions on their basis have shown that composition of structure, the mass of \%:oxyethylated fatty acids of gossypol pitch $40,0-50,0$; dimethylphosphite - 0,5-0,6; trietanolamine-0,5-0,7; "Fosfenoks N-6" - 15,0-20,0; the solvent - the rest, treats destructive agencies of wate oil demulsifierin case of simultaneous protection of systems of collection, transport and preparation of oil against corrosion and the asphaltene deposits and can be used in case of oil dehydration, in case of a pipe demulsifieron objects of petrocollection, industrial plants of preparation of oil. The main component oxyethylated fatty acids of gossypol pitch - is received on the basis of waste of oil and fat production.

Corresponding Author:- Saltanat Elikbayevna Baibotayeva. 


\section{Introduction:-}

The problem of creating complex multi-functional reagents for the oil and gas industry meets the basic priorities of socio-economic development of the Republic of Kazakhstan, as its decision will contribute to the sustainable growth of Kazakhstan's economy by accelerating diversification through industrialization and infrastructure development of individual regions. In recent decades, there is observed a rapid increase in oil and gas industry of Kazakhstan and its active influence on the real sector of the world economy [1.2]. 2015 has become very difficult for Kazakhstan. The low prices of oil have greatly affected the economy of the country, but despite this, many oil-extracting companies operating in the same mode. However, the exploitation of oil fields of Kazakhstandirected, first of all, to achievement of the maximum oil extraction has led to distinct increase of a share of hard-to reserves and decrease in a share of active reserves of oil today. Together with oil about $90 \%$ of the water forming with it the resistant water oil emulsions stabilized by the natural surface-active substances (SAS) and pitches are extracted. Today the serious problems that exist in the oil industry, are the fight against corrosion, with the formation of stable water-oil emulsions and asphaltene deposits (AFS). These phenomena greatly complicate the extraction of oil from wells, negatively affect the operation of oilfield equipment, pipeline communications. Especially this question is actual for the fields in which the oil is extracted high-paraffinic oil, for example, for the Kumkol field. Due to the high stability of these emulsions can achieve their failure only by demulsifiers. As the cost of demulsifier (emulsion breakers) is quite large, the problem of reducing their consumption by increasing the efficiency of reagents is very actual. One of the effective directions in creation of new demulsifieris the compounding of various structure allowing, in the presence of a certain set of initial components, to receive structures with various properties $[3,4]$.

The problem of effective conversion of secondary resources with receipt of competitive products also is actual for all industrially developed countries. However, despite the importance and the economic feasibility of the most complete recycling of secondary resources, the level of their current use is still insufficient and far from optimal. Considering the potential of oil and fat enterprises southern Kazakhstan, the problem of efficient processing of secondary resources oil industry goes beyond the industry and gets the state value [5]. The main components of the secondary resources obtained in the processing of vegetable oils, and are tar distillation of fatty acids. In our works the problems designated above are solved in a complex due to use of waste of oil and fat production - gossipolovy pitch for receipt of composite demulsifierby use method surfactant of various structure and functional purpose.

Until recently, the main condition for achieving the required efficiency of emulsion breakers considered their selection for specific oil fields. Moreover, this selection is carried out basically only empirically: a bust of possible mixtures of several embodiments of the reagents and test their effects on specific water-oil emulsions. However, according to the authors [4], because of the lack of scientific bases of obtaining composite demulsifier significantly enhance their effectiveness has not occurred in the last half-century. Up to now based on a wide range of proposed demulsifiers not created a universal reagent, which is associated both with the properties of the produced oil (composition, physico-chemical and colloid-chemical properties of the oil, salinity of formation water, composition and quantity of mechanical impurities, water cut oil temperature) and with a variety of extraction techniques [6]. This circumstance suggests specific to each region's requirements demulsifiers and do not allow for drainage of oil through the universal for all demulsifiers regions, especially since many factors are variable, not only in the transition from one field to another, but in time within a particular object. One of the direction in the solution of this task is creation of compositions which part is several individual connections, in mix showing synergy effect; can be included surfactant with properties of a wetting agent, dispersant, coagulant in structure of composition, etc. Such compositions, as a rule, along with properties inherent in the separate components which are their part possess a complex of the properties which are result of their combined action. This way allows to strengthen the most important characteristics of reagents and to expand their functional action [7-9]. In recent years the range of composite demulsifierusing imported components has considerably extended. However the high price of import components increases the final cost of compositions on their basis. Accumulating of AFS in flowing parts of an oilindustry equipment and internal surfaces of pipelines leads to acceleration of depreciation of the equipment, decrease in coefficient of productivity of the field and overall performance of pumping units therefore there is a need of carrying out scheduled maintenance for removal of AFS, their decomposition and the prevention of education. Until recently the main methods of fight against deposits of AFS were thermal or machining (with use of scrapers of various configuration) and a chemical method. Analysis of existing ways of dealing with the formation 
of stable emulsions and water paraffin emulsions AFS shows that the most commonly used and are promising chemical methods [10]. They involve the use of reagents for removing already formed paraffin deposits, deposits their prevention and destruction of oil-water deposits. The most widely used agents, which have dispersing properties. They contribute to the creation of the fine system, which imposed the flow of oil and prevents the formation of wax crystals on the walls of the well, and are able to break down persistent oil emulsion. There are agents which act as inhibitors, creating on the inner surface of metal tubes hydrophilic film, prevent adhesion of the wax crystals on the surface of the tubes. Such reagents include nonionic surfactants including oxyethylated fatty acid gossypol pith. In this regard, an urgent task is to develop new composite nonionic demulsifiers comprehensive actions on the basis of best available surfactants domestic production or origin (for waste of various products).

\section{Materials and methods:-}

The purpose of the conducted researches was studying of complex action of the new composition received by use of waste of the oil and fat industry as a demulsifiers and corrosion inhibitors and wax formation (paraffin). Routine preprocessing of oil (dehydration, desalting) is possible using traditional methods: thermal, chemical, and their combination, as well as with the use of an electric field. However, in such cases, the necessary intensification - an increase in temperature of oil processing, the introduction of the flow of high-dose-selective reagents demulsifiers, increasing electric field strength - leads to a significant appreciation of the cost of the oil production process. Therefore, the use of only one agent efficiency and comprehensive action to obtain commercial oil economically justified. The objects of research were the compositions of different structure created on the basis of oxyethylated fatty acids of gossypol pitch(OFAGP), the results of the study are published by us earlier $[11,12]$ and other surfactants and additives.Dimethylphosphite (DMPH) was consistent with the TU-6-36-5763445-6-88; triethylamine (TEA) - TU 6-02-916-79; "Fosfenoks H-6 'was prepared by conventional interaction with phosphorus oxychloride and used Neonol according 6-40-5763445-23-90 TU, as a corrosion inhibitor. As the solvent, it is checked using many organic liquids such as methanol technical, petroleum toluene, xylene, ethylbenzene, and mixtures thereof al., but the properties of the composition is not changed. Gossypol pitch is a homogeneous viscous-flow mass from dark brown till black color. Gossypol pitch contains from 52 to $64 \%$ of crude fatty acids (FA) and their derivatives, other part - the products of condensation and polymerization of gossypol and its transformations which are formed in case of oil extraction, mainly, in the course of distillation of (FA) of soap stocks. We in the course of work have used gossypol pitch of structure: $98,29 \%$ of organic substances; $1,71 \%$ of inorganic substances; $100 \%$ of ether-soluble substances; the acid number is equal to $68,5 \mathrm{mg} \mathrm{KOH}$; iodine value - 97; saponification number - $200 \mathrm{mg} \mathrm{KOH} / \mathrm{g}$; essential value - $135 \mathrm{mg} \mathrm{KOH}$; hydroxyl number - 91\%; FA released at saponification - 64\%; 38\% of low-fat substances; $0,2165 \%$ of phosphorus (in terms of $\mathrm{P}_{2} \mathrm{O}_{5}$ ); 8,78\% of calcium in calcium salts of gossypol pitch. Gossypol pitch also contains a quantity of isomers of tocopherol which at saponification are localized in not saponified part [13]. The structure of the cleared fatty fraction established by method of a gas-liquid chromatography (GLH) can be presented as follows, \%: nonsaturated acids: linoleic - 31,1, linolenic - 25,2, olein 19,3, saturated acids: palmitic 18,0, stearic $-2,1$, myristic $-1,4$, arachic $-0,5$, the content of foreign impurity (gossypol, gossypol ethers, substitutedpolyphenols, sterols, tocopherols) about 1,2-1,3\%.This structure has been used for receiving OFAGP.

Oxyethylated fatty acids of gossypol pitch (OFAGP) received on developed by authors [14, 15], the cleared OFAGP have received the name "Gossilvan-3".

Production testing of compositions were carried out on oils of the field Kumkol and model emulsions on their basis by the following technique. The incoming emulsion was selected from the sample port established on a general collector to a point of giving of a demulsifiers. In tests of an emulsion dosed the tested demulsifier with certain specific expenses of oil, then tests stirred up 300 times within $2 \mathrm{~min}$. and defended $90 \mathrm{~min}$. at a temperature of 40 ${ }^{\circ} \mathrm{C}$. Through certain periods fixed amount of the selected water and quality of the section of phases oil - water. In 90 min. a sediment the selected water was deleted with the special syringe, the remained oil together with the interfacial layer was centrifuged within $5 \mathrm{~min}$. in case of rotating speed of $2000 \mathrm{~min}$.-1. Centrifugation determined residual content of water in oil and an intermediate layer, and the remained water after centrifugation was emitted in the form of a free phase and the residual not destroyed emulsion. The more residual water in oil remains in the form of not destroyed emulsion, the efficiency of action of a demulsifier is lower, the risk of education and accumulating of intermediate layers in the settling equipment is more. In control test (without reagent) before and after a sediment also by method of centrifugation determined the aggregate stability of an emulsion characterizing degree of stability of an emulsion, its capability to self-damage in the course of upholding [16,17]. Determination of efficiency of protective action from AFS was carried out by the following technique: in reservoir of $250 \mathrm{ml}$ placed $25 \mathrm{ml}$ of 
reservoir water of a general mineralization of $200 \mathrm{~g} / \mathrm{l}$ in a conic flask and added to it $5 \mathrm{mkl}$ reagent. Then placed in a flask 1,25g. AFS also heated on a water bath to complete fusion of deposits, carefully mixing flask content rotation. After that mix in a flask was cooled under a water stream to $12-14{ }^{\circ} \mathrm{C}$, stirring up it roundabouts. At the same time fixed dispergation of AFS, sticking and puttying of flask walls by them.

Dispergation: results are considered excellent at the size of particles of AFS of 0,1-3 mm (100\%), good - 0,1-5 mm $(50-70 \%)$, satisfactory - 0,1-7 $\mathrm{mm}(30-50 \%)$, more than $7 \mathrm{~mm}$ - unsatisfactory.

Sticking of AFS to walls of a glass conic flask in $\%$ of a working surface: the result is excellent if sticking makes up to $5 \%$, good - to $10 \%$, satisfactory - to $40 \%$, unsatisfactory - above $40 \%$.

Sealing of walls of a flask in \% of a working surface: the result is excellent if puttying no more than 5\%, good - to $20 \%$, satisfactory - to $50 \%$, unsatisfactory - more than $50 \%$.

Paraffin deposits in real oil-field systems never consist for $100 \%$ from paraffin, and represent mix of paraffin (20$70 \%$ of masses.), oil (up to $45 \%$ of masses. and more), resinous-asphaltenic materials (RAM) (20-40\% of masses.), silica-gel resins, oils, water and mechanical impurity. Therefore researches were conducted also on model systems of constant structure, the maintenance of RAM in crude Kumkol oil was brought to a constant - $15 \%$, adding to oil complex mix of the above-stated structure, with the subsequent heating of system to $65{ }^{0} \mathrm{C}$.

Testing of developed structures for corrosion protection carried out on model reservoir water according to GOST 9.502-82. As the corrosion environment used model of reservoir water, reservoir water of the Kumkol field, similar on structure. Efficiency of the declared structures on corrosion activity was estimated on their protective effect on a formula:

$$
Z=\frac{\Delta P-\Delta P_{1}}{\Delta P} \cdot 100 \%,
$$

where: $\Delta P$-corrosion losses on a sample in the corrosion environment without structure, $\mathrm{g}$; $\Delta P_{1}$-corrosion losses on a sample in the corrosion environment with structure, $\mathrm{g}$. , and then recalculated the received sizes of rather similar indicator of a prototype, $\%$.

\section{Results and their Discussion:-}

In the result of experiments the structure for dehydration and an desalting of oil, inhibition of corrosion of the oilfield equipment and AFS is created on the basis of OFAGP of gossypol pitch and includes also dimethylphosphite, triethylamine, inhibitor of corrosion "Fosfenoks-N-6" and solvent at the following ratio of components, mass of \%: OFAGP - 40,0-50,0; dimethylphosphite - 0,5-0,6; tri etanol amine-0,5-0,7; "Fosfenoks N-6" - 15,0-20,0; solvent the rest. This structure has received the name "Gossilvan-3K6".Structures were prepared by consecutive mixture of dimethylphosphite with solvent in the reactor supplied with a mixer with the speed of $100 \mathrm{rpm}$ at $70^{\circ} \mathrm{C}$ within 5 min. The received mix was cooled to $20^{\circ} \mathrm{C}$ and added to it triethylamine when hashing at $20^{\circ} \mathrm{C}$ within 5 min., then when hashing within 5 min. mixed in "Fosfenoks N-6", further added OFAGP when hashing 10 min. and led up solvent volume to calculated when hashing within $10 \mathrm{~min}$.

In tables 1-3, shown how properties of composition depending on her structure change.

Table 1:- Effect of composition on demulsifying activity and protective effect against corrosion compositions in dosage $50 \mathrm{~g} / \mathrm{m}$

\begin{tabular}{|l|l|l|l|l|l|l|}
\hline \multirow{2}{*}{$\begin{array}{c}\text { No of } \\
\text { variation }\end{array}$} & \multicolumn{4}{|c|}{ Components of structure, mass of \% } & \multicolumn{2}{l|}{$\begin{array}{l}\text { Quality indicators, (options 2-13, in \% in } \\
\text { comparison with option 1) }\end{array}$} \\
\cline { 2 - 7 } & OFAGP & DMPH & TEA & Fosfenoks & $\begin{array}{l}\text { The demulsifying } \\
\text { activity }\end{array}$ & $\begin{array}{l}\text { Protective effect of } \\
\text { corrosion }\end{array}$ \\
\hline 1 & 45 & - & - & - & 100 & 10 \\
\hline 2 & 45 & 0.5 & - & - & 100 & 25 \\
\hline 3 & 45 & 0.5 & 0.5 & - & 110 & 30 \\
\hline 4 & 45 & 0.5 & 0.5 & 20 & 120 & 90 \\
\hline 5 & 30 & - & - & - & 80 & 8 \\
\hline 6 & 30 & 0.5 & - & - & 80 & 15 \\
\hline
\end{tabular}




\begin{tabular}{|l|l|l|l|l|l|l|}
\hline 7 & 30 & 0.5 & 0.5 & - & 82 & 22 \\
\hline 8 & 30 & 0.5 & 0.5 & 20 & 90 & 84 \\
\hline 9 & 70 & - & - & - & 100 & 12 \\
\hline 10 & 70 & 0.5 & - & - & 100 & 22 \\
\hline
\end{tabular}

From the Table 1 it follows that demulsifying efficiency of the compositions at a dose of $50 \mathrm{~g} / \mathrm{t}$ is high and has not decreased by a complication composition, due to the fact that the efficiency of dehydration "Gossilvan-3" containing ethoxylated fatty acids and derivatives gossypol pitch exceeds parameters most famous compositions for demulsification of paraffin oils. By reducing the content of OFAGP demulsifying efficiency decreases, in their absence, the drug does not exhibit the properties of the emulsion breaker (demulsifier). Entering of additives of DMPH and TEA increases the demulsifying efficiency for 10-20\%, and the additive "Fosfenoksa N-6" gives to composition anticorrosive properties.

Otherwise, an effect of changing the component ratio on the rheological properties of emulsions (Table 2) and the effect of inhibition of AFS (Table 3). Complex viscosity at introduction to structure of a emulsion breaker (demulsifier) of DMPH and TEA (only at joint action) decreases by 2,0-2,5 times, but only when the additive concentration of not more than $1 \mathrm{wt} \%$, at increase of their contents above this value complex viscosity of a water oil emulsion increases again.

Table 2:- Efficiency of decrease of complex viscosity of a water oil emulsion.

\begin{tabular}{|l|l|l|l|}
\hline \multirow{2}{*}{ Number of option acc. to tab. 1} & \multicolumn{3}{|c|}{ Complex (viscous and elastic) viscosity $\mathrm{mPa}^{*}$ s. at a temperature of about ${ }^{\circ} \mathrm{C}$} \\
\cline { 2 - 4 } & 5 & 15 & 25 \\
\hline Initial model emulsion & 20100 & 9200 & 4500 \\
\hline 1 & 19900 & 9100 & 4450 \\
\hline 2 & 1900 & 9050 & 4440 \\
\hline 3 & 10100 & 4005 & 2100 \\
\hline 4 & 10130 & 4110 & 2200 \\
\hline
\end{tabular}

The effectiveness of inhibition of AFS increases when entering in composition in addition to OFAGP of all other components in optimum concentration, reaching a maximum in case of their joint presence (option 4), increase in concentration of the designated concentration of increase of inhibition of AFS operating a component above does not cause. In case of lack of OFAGP as a part of composition the effect of inhibition of AFS is practically absent that demonstrates emergence of synergetic effect concerning AFS inhibition at the expense of an optimum ratio of all components.

Table 3:- Efficiency of inhibition of AFS

\begin{tabular}{|c|c|c|c|c|c|}
\hline \multirow{2}{*}{$\begin{array}{ll}\text { Number } & \text { of } \\
\text { option acc. } & \text { to } \\
\text { tab. } 1 & \end{array}$} & \multirow{2}{*}{$\begin{array}{l}\text { Mass fraction of } \\
\text { residual water in } \\
\text { oil }\end{array}$} & \multicolumn{3}{|c|}{ Efficiency of inhibition of AFS } & \multirow{2}{*}{$\begin{array}{l}\text { Content of oil in } \\
\text { waste water, } \\
\mathrm{mg} / \mathrm{ml}\end{array}$} \\
\hline & & $\begin{array}{l}\text { Dispersion, } \\
\text { (disability) } \mathrm{mm}\end{array}$ & $\begin{array}{l}\text { Puttying, } \\
\text { (sealing) } \\
\%\end{array}$ & $\begin{array}{l}\text { Sticking, } \\
\text { (balling) } \\
\%\end{array}$ & \\
\hline $\begin{array}{l}\text { Initial model } \\
\text { emulsion }\end{array}$ & - & $>5$ & about 50 & about 40 & - \\
\hline 1 & \multicolumn{5}{|c|}{ The effect of inhibition of AFS is absent } \\
\hline 2 & 0,5 & $>5$ & 40 & 35 & 60 \\
\hline 3 & 0,5 & 4 & 20 & 17 & 45 \\
\hline 4 & 0,5 & 1 & 0 & 4 & 27 \\
\hline 13 & \multicolumn{5}{|c|}{ The effect of inhibition of AFS is absent } \\
\hline
\end{tabular}

As developed on the basis of laboratory research reagent demulsifier "Gossilvan-3K6" are technical and economic interest to the oil-extracting industry, there was a feasibility of production of a pilot batch of composite reagent and its testing in trade conditions. Table 4 shows the results of using the reagent composition "Gossilvan-3K6" for the main property - for dehydration and desalting of crude oil. Testing of demulsifier was held in the temperature and time modes as close as possible to real conditions of preparation on oil fields of the Kumkol field. 
Table 4:- Results of dehydration of oil of the Kumkol field in field semi-industrial tests. *

\begin{tabular}{|c|c|c|c|c|c|c|c|c|c|}
\hline \multirow{2}{*}{$\begin{array}{l}\text { Indicators } \\
\begin{array}{l}\text { Specific flow } \\
\text { rate }, \mathrm{g} / \mathrm{m}^{3}\end{array}\end{array}$} & \multirow{2}{*}{$\begin{array}{l}\text { Variants } \\
\text { Time, min }\end{array}$} & \multirow{2}{*}{$\begin{array}{l}\text { Without } \\
\text { demulsifier } \\
-\end{array}$} & \multicolumn{3}{|c|}{ Dissolvan 4411} & \multicolumn{2}{|c|}{ FLACK-D-12 } & \multicolumn{2}{|c|}{ Gossilvan-3K6 } \\
\hline & & & 80 & 120 & & & 120 & 40 & 50 \\
\hline \multirow{5}{*}{$\begin{array}{l}\text { Amount of } \\
\text { the emitted } \\
\text { water in time, } \\
\text { in a \% of } \\
\text { total amount }\end{array}$} & 3 & - & 2 & 4 & & & 2 & 3 & 4 \\
\hline & 10 & - & 22 & 30 & & & 36 & 33 & 41 \\
\hline & 60 & - & 64 & 70 & & & 66 & 67 & 72 \\
\hline & 120 & 10 & 70 & 80 & & & 85 & 80 & 86 \\
\hline & \multicolumn{2}{|l|}{ Object } & \multicolumn{7}{|l|}{ Indicators } \\
\hline \multirow{4}{*}{$\begin{array}{l}\text { Supervision } \\
\text { of quality } \\
\text { after a } \\
\text { sediment }\end{array}$} & Water & Sat. & Good & \multicolumn{2}{|c|}{ Good } & Good & Good & Good & Good \\
\hline & $\mathrm{s} / \mathrm{f}$ & $\mathrm{Bad}$ & Good & \multicolumn{2}{|c|}{ Good } & Good & Good & Good & Good \\
\hline & Oil & $\mathrm{Bad}$ & Good & Exc. & \multicolumn{2}{|c|}{ Sat. } & Exc. & Good & Exc. \\
\hline & Type of study & Object & \multicolumn{7}{|l|}{ Indicators } \\
\hline \multirow[t]{5}{*}{$\begin{array}{l}\text { Results of } \\
\text { centrifugation }\end{array}$} & \multirow{3}{*}{$\begin{array}{l}\text { Residual } \\
\text { content of water } \\
\text { in commodity } \\
\text { oil, } \%\end{array}$} & $\begin{array}{l}\text { cent.f. } \\
\text { ph. }\end{array}$ & Indefined & 0,3 & 0,3 & 0,7 & 0,1 & 0,5 & 0,1 \\
\hline & & I.1. & Indefined & 0,5 & 0,4 & 0,9 & 0,2 & 0,6 & 0,2 \\
\hline & & water & Indefined & 0,7 & 0,7 & 1,5 & 0,3 & 0,8 & 0,3 \\
\hline & \multirow{2}{*}{$\begin{array}{l}\text { Residual } \\
\text { content of water } \\
\text { in full } \\
\text { oil, } \%\end{array}$} & $\begin{array}{l}\text { cent.f. } \\
\text { ph. }\end{array}$ & 30 & 1,9 & 1,5 & 3,8 & 1,7 & 1,8 & 1,4 \\
\hline & & I.1. & 60 & 1,0 & 0,8 & 1,6 & 1,2 & 1,4 & 1,1 \\
\hline
\end{tabular}

Used the method "BOTTLE TEST". Conditions: initial centrifugation: $10 \%$ of water in a free form, $60 \%$ of the int. of a layer, $70 \%$ of water only; temperature $-40{ }^{\circ} \mathrm{C}$, test duration - 2 hours. Explanations to the table: S/f- the section of the phases "oil-water"; cent.f.ph.- the water which is emitted at centrifugation in a free phase; I.1.- an intermediate layer (not destroyed emulsion) at oil centrifugation.

The analysis of the received results shows that new reagent Gossilvan-3K6 on the demulsifying activity doesn't concede to the best samples of import demulsifier and can be used for dehydration and an desalting of oil. The demulsifying efficiency of reagent at a dosage of $50 \mathrm{~g} / \mathrm{t}$ is characterized by the following indicators for sizes: residual content of water in oil, $\%$ of masses, $-0,10$; residual content of salts in oil, $\mathrm{mg} / \mathrm{l},-51$.

\section{Conclusions:-}

Thus, the objective - development of new composition of complex action on the basis of inexpensive and available surfactant of national production or an origin (for waste of various productions) for an oil-extracting industry - is reached, the semi-industrial testing of compositions executed on paraffinic oil and model emulsions on their basis have shown that composition of structure, the mass of \%: OFAGP - 40,0-50,0; dimethylphosphite - 0,5-0,6; trietanolamine-0,5-0,7; "Fosfenoks N-6" - 15,0-20,0; the solvent - the rest, treats destructive agencies of water oil emulsions in case of simultaneous protection of systems of collection, transport and preparation of oil against corrosion and AFS and can be used in case of oil dehydration, at a pipe demulsification on objects of in-field flowline, industrial plants of preparation of oil and also as independent inhibitor of corrosion in oxygen-containing and in hydrogen sulfide-containing media. 


\section{Literature:-}

1. O.I. Egorov, O.A. Chigarkina, A.S. Baimukhanov: Oil and gas complex of Kazakhstan: problems of development and effective functioning. - Almaty Atamyra, 2003. - 536 p.

2. Facts and figures for the oil and gas industry in Kazakhstan for 2015 year. http://yvision.kz/post / 677,935.

3. Chemical reagents for oil treatment to transport: Research and technological development of the oil and gas industry: report for the Eighth International Scientific Nadirov readings / G.I. Boiko, N.P. Lubchenco, T.P.Maimak, E.M. Shaikhutdinov, E Orazbekuly, M.K. Sabdalieva, AV Ignatovich - Almaty, 2010. - P. 150155.

4. L.P. Semihina, A.G. Perekupka, D.V. Plotnikov, D.V. Zhuravsky, Increase of efficiency of demulsifier by receipt of their nanomodifications. .// Annals of Tyumen State. University.- 2009, № 6. - p.88-93.

5. B. Ospanov development of cotton-textile cluster in South Kazakhstan region - Realities and Prospects .// Kaz. True. - 05.11.2009.

6. D.N. Levchenko, N.V. Bergshteyn A.D. Khudyakov and others. Oil-water emulsions and methods of their destruction -.M .: Chemistry. - 1967. - 199 p.

7. N.Yu. Bashkirtseva Composite demulsifiers for oil treatment.Abstract (autoabstract) ......... candidate.tehn. Sciences. - Kazan. - 1996.

8. V.F. Lesnichyi, V.P. Bazhenov, L.M. Shipiguzov and others. The composition for oil dehydration and desalting.RF Patent №2105789. -1998. // BI №6, 1998.

9. G.A. Tudry, O.A. Varnavskaya, L.K. Khvatova and others. The composition for dehydration and desalting of oil.Patent RF №2126030. -1999. // BI №4, 1999.

10. A.N. Markin, R.E. Nizamov, S.V. Sukhoverkhov Oilfield chemistry: a practical guide. - Vladivostok: Dal'nauka. - 2011. - 288 p.

11. K.S. Nadirov, G.Zh. Bimbetova, A.D.Baibotayeva, N.H. Nurashev. Getting nanomodifieddemulsifier by compounding surfactants with different structures.Materials 6th All-Russian scientific-practical conference with international participation "Problems and innovation of modern society. - Astrakhan, 2014. - p. 347-354.

12. K.S. Nadirov, M.K. Zhantasov, G.Zh. Bimbetova, S.M. Ermenov, M.A. Zhusupaliev, N.Sh. Otarbayev. Hydroxyethylation of fatty acids of tars of cotton oil for receiving surfactant of the demulsifying action.Material for the X International scientific-practical conference "Scientific understanding Naynovite 2014", T. 33.Technologies. - Sofia .: "ByalGRAD-BG" OOD, 2014. - p. 69-74.

13. A.I. Glushenkova, I.P. Nazarova. Gossypol and its derivatives, and its using.- Tashkent: Pham - 1993.- 78 p.

14. K.S. Nadirov, M.K. Zhantasov, G.Zh. Bimbetova, A.K. Orynbasarov Development of hardware and technological registration of process of the hydroxyethylation of fatty acids of gossypol pitch. The National Association of Scientists.Monthly magazine, №3 (8). - Ekaterinburg. - 2015.-P.160-163.

15. K.S. Nadirovandothers.Demulsifier for dehydration and desalting of crude oil.Innovative patent (19) KZ (13) A4 (11) 26788. Bull. № 4.publ. 15.04. 2013.

16. N.I. Magomedsherifov. Preparation of commercial oil deposits in the OJSC "Sibneft - Noyabrneftegas (NNG)". M .: Monograph - 2005. - P. 86.

17. N.I. Magomedsherifov. Research and development of methods of dehydration ofwell production in oil fields. Abstract candidate. tehn. Sciences. - Tyumen. - 2008. 